\title{
Interleukin 1 Trials in Cancer Patients: A Review of the Toxicity, Antitumor and Hematopoietic Effects
}

\author{
Salvatore Veltri, John W. Smith II \\ The University of Michigan Medical Center, Department of Internal Medicine, Division of \\ Hematology/Oncology, Ann Arbor, Michigan, USA
}

Key Words. Interleukin $1 \cdot$ Neoplasms $\cdot$ Review $\cdot$ Clinical trials $\cdot$ Toxicity $\cdot$ Antitumor effects $\cdot$ Hematopoietic effects

\begin{abstract}
Clinical trials of interleukin $1 \alpha(\mathrm{IL}-1 \alpha)$ and IL-1 $\beta$ have been completed that assess the toxicities of these cytokines as well as their hematopoietic and antitumor effects. Both forms of IL-1 recognize the same cell surface receptors and have similar toxicities and similar biological activities. Toxicities including fever, flu-like symptoms and dose-limiting hypotension can be severe yet manageable, and IL-1 can be given safely to human cancer patients. Most toxicities and biological effects appear to be dose-related. IL-1 alone has little antitumor activity against melanoma, renal cell carcinomas
\end{abstract}

or other malignancies. The hematopoietic effects, including megakaryocytopoietic effects, are modest and are probably not worth the toxicity necessary to achieve them. However, IL-1 seems to endow certain progenitor cells with responsiveness to other hematopoietic cytokines including colony-stimulating factors and IL-3. One potential application of IL1 is to help expand bone marrow ex vivo following stem cell harvest, which could allow further chemotherapy dose escalations in chemotherapy-sensitive tumors. The Oncologist 1996;1:190-200

\section{INTRODUCTION}

In recent years, biologic response modifiers have been studied in an effort to expand the oncologist's arsenal in the battle against cancer. Interleukin 1 (IL-1) was one of the first biologic response modifiers identified, but clinical studies of interferon (IFN), IL-2, tumor necrosis factor (TNF) and colony stimulating factors (CSFs) preceded IL-1 trials. IL-1 was first identified as an endogenous pyrogen during research on fever dating back to the 1940s [1]. This protein was found in acute granulocytic exudate fluid, and when injected into humans or animals, it produced fever. In the 1970s, the purified product demonstrated other effects including induction of neutrophilia, apparent colony stimulating activity, augmentation of thymocyte and $\mathrm{T}$ cell proliferation to mitogens, and induction of nonspecific resistance to infection [2]. IL-1 $\alpha$ and IL-1 $\beta$ were both cloned and sequenced in 1984 [3]. Both forms of IL-1 recognize the same cell surface receptors and have similar biological activity, but they are distinct gene products with only $27 \%$ homology [4].

The effects of IL-1 are multiple, involving immunomodulation, inflammation, wound healing, hematopoiesis, metabolism and the endocrine system [2]. IL-1 also has a number of properties potentially useful in the treatment of cancer, including direct antiproliferative activity against certain human tumor cell lines and several murine tumors $[5,6]$, the activation of effector cells in vitro [7-9], the ability to induce hemorrhagic necrosis and the inhibition of tumor angiogenesis [10], and the induction of secondary cytokines that may have direct antiproliferative or immunostimulatory activities [2, 11]. In addition, IL-1 has the capacity to protect and restore the bone marrow from radiation or chemotherapy-induced injury [12, 13]; it can stimulate proliferation of multipotential bone marrow progenitors in the presence of other colony stimulating factors [14] and also has immunostimulating properties that might be helpful in the treatment of cancer patients at high risk for infection [15].

Phase I studies of IL-1 in cancer patients were begun in 1989 to determine the maximum tolerated dose (MTD) by various schedules and routes of administration. Phase II trials of IL-1 to assess antitumor activity in melanoma and renal cell carcinoma have

\section{FOR FURTHER INFORMATION ON}

the emergence of thrombopoietin, please see Dr. David J. Kuter's excellent article "Thrombopoietin: Biology and Clinical Applications," featured in the inaugural issue of The Oncologist 1996;1:88-97. 
been conducted. IL-1 has also been tested in combination with chemotherapy to determine the

Table 1. Common side effects of IL-1 $\alpha$ and IL-1 $\beta$

$\Delta$ Fever

$\Delta$ Chills, rigors

$\Delta$ Nausea

$\Delta$ Vomiting

$\Delta$ Fatigue

$\Delta$ Headache

$\boldsymbol{\Delta}$ Myalgia, arthralgia

$\Delta$ Hypotension

$\boldsymbol{\Delta}$ Tachycardia

$\Delta$ Abdominal pain

$\Delta$ Peripheral vein phlebitis

$\Delta$ Confusion, somnolence*

$\Delta$ Dyspnea*

$\Delta$ Edema* $^{*}$

$\Delta$ Prerenal azotemia*

*Noted only at the higher doses of IL-1. consistent with a pulmonary capillary leak phenomenon. However, these patients did not exhibit the severe pulmonary toxicities commonly observed with high-dose IL-2 therapy. Severe abdominal pain without diarrhea and more severe central nervous system toxicity were observed in a few patients treated at higher doses of IL-1.

Investigators at Memorial Sloan-Kettering Cancer Center studied escalating doses (from $0.002 \mu \mathrm{g} / \mathrm{kg}$ to $0.1 \mu \mathrm{g} / \mathrm{kg}$ ) of recombinant human (rHu) IL-1 $\beta$ (Syntex; Palo Alto, CA) given by short i.v. infusion for two days in patients with gastrointestinal cancer [17]. Toxicities included fever, rigors and headache in the majority of patients. Hypotension was the dose-limiting toxicity and was observed in three of five patients at the highest dose level $(0.1 \mu \mathrm{g} / \mathrm{kg})$.

The Biological Response Modifiers Program (BRMP) of the National Cancer Institute (NCI) conducted a phase I trial of IL-1 $\alpha$ (Dainippon; Osaka, Japan) given by i.v. infusion over $15 \mathrm{~min}$ for seven days in patients with advanced malignancies [16]. An inpatient MTD with maximal supportive measures including blood pressure support with pressors was determined to be $0.3 \mu \mathrm{g} / \mathrm{kg}$. A group of patients was also treated with indomethacin and IL- $1 \alpha$ to determine if the toxicity of IL- $1 \alpha$ could be ameliorated by inhibitors of prostaglandin synthesis as suggested by animal studies [18];

\begin{tabular}{|c|c|c|c|}
\hline Investigators & Type of IL-1 & Doses Route Schedule & MTD \\
\hline $\begin{array}{l}\text { Crown et al. [17] } \\
\text { (MSKCC) }\end{array}$ & $\begin{array}{l}\text { IL-1 } \beta \\
\text { (Syntex) }\end{array}$ & $\begin{array}{c}0.002 \mu \mathrm{g} / \mathrm{kg}-0.1 \mu \mathrm{g} / \mathrm{kg} \text { i.v. } \\
\text { over } 30 \mathrm{~min} \\
\text { q.d. } \times 2 \text { days }\end{array}$ & $\begin{array}{c}0.068 \mu \mathrm{g} / \mathrm{kg} \\
\text { (without pressors) }\end{array}$ \\
\hline $\begin{array}{l}\text { Smith et al. [19] } \\
\text { (BRMP/NCI) }\end{array}$ & $\begin{array}{c}\text { IL-1 } \alpha \\
\text { (Dainippon) }\end{array}$ & $\begin{array}{c}0.01 \mu \mathrm{g} / \mathrm{kg}-1.0 \mu \mathrm{g} / \mathrm{kg} \text { i.v. } \\
\text { over } 15 \mathrm{~min} \\
\text { q.d. } \times 7 \text { days }\end{array}$ & $\begin{array}{c}0.3 \mu \mathrm{g} / \mathrm{kg} \\
\text { (with pressors for blood } \\
\text { pressure support) }\end{array}$ \\
\hline $\begin{array}{l}\text { Steis et al. [20] } \\
\text { (BRMP/NCI) }\end{array}$ & $\begin{array}{l}\text { IL-1 } 1 \beta \\
\text { (Syntex) }\end{array}$ & $\begin{array}{c}0.01 \mu \mathrm{g} / \mathrm{kg}-1.0 \mu \mathrm{g} / \mathrm{kg} \text { i.v. } \\
\text { over } 15 \mathrm{~min} \\
\text { q.d. } \times 7 \text { days }\end{array}$ & $\begin{array}{c}0.3 \mu \mathrm{g} / \mathrm{kg} \\
\text { (with pressors) }\end{array}$ \\
\hline $\begin{array}{l}\text { Dennis et al. [21] } \\
\text { (NYUMC) }\end{array}$ & $\begin{array}{c}\text { IL-1 } \alpha \\
\text { (Immunex) }\end{array}$ & $\begin{array}{c}0.08 \mu \mathrm{g} / \mathrm{m}^{2}-5.0 \mu \mathrm{g} / \mathrm{m}^{2} \text { i.v. } \\
\text { over } 2 \mathrm{~h} \\
\text { q.d. } \times 5 \text { days }\end{array}$ & $\begin{array}{c}2 \mu \mathrm{g} / \mathrm{m}^{2} \\
\text { (without pressors) }\end{array}$ \\
\hline $\begin{array}{l}\text { Kanz et al. [22] } \\
\text { (Univ. of Frieburg } \\
\text { Germany) }\end{array}$ & $\begin{array}{l}\text { IL-1 } \beta \\
\text { (Syntex) }\end{array}$ & $\begin{array}{c}10-100 \mathrm{ng} / \mathrm{kg} \\
\mathrm{SQ} \\
\text { q.d. } \times 7 \text { Days }\end{array}$ & (MTD not reached) \\
\hline $\begin{array}{l}\text { Janik et al. [23] } \\
\text { (BRMP/NCI) }\end{array}$ & $\begin{array}{c}\text { IL-1 } \alpha \\
\text { (Dainippon) }\end{array}$ & $\begin{array}{l}0.001 \mu \mathrm{g} / \mathrm{kg}-0.1 \mu \mathrm{g} / \mathrm{kg} \\
\text { intratumoral injection } \\
(\mathrm{SQ} / \mathrm{cut} .) \\
\text { q.d. } \times 5 \text { days }\end{array}$ & (MTD not reached) \\
\hline Abbreviations: & \multicolumn{3}{|c|}{$\begin{array}{l}\text { MTD = maximum tolerated dose } \\
\text { MSKCC = Memorial Sloan-Kettering Cancer Center } \\
\text { BRMPNCI = Biological Response Modifiers Program/National Cancer Institute } \\
\text { NYUMC = New York University Medical Center }\end{array}$} \\
\hline
\end{tabular}




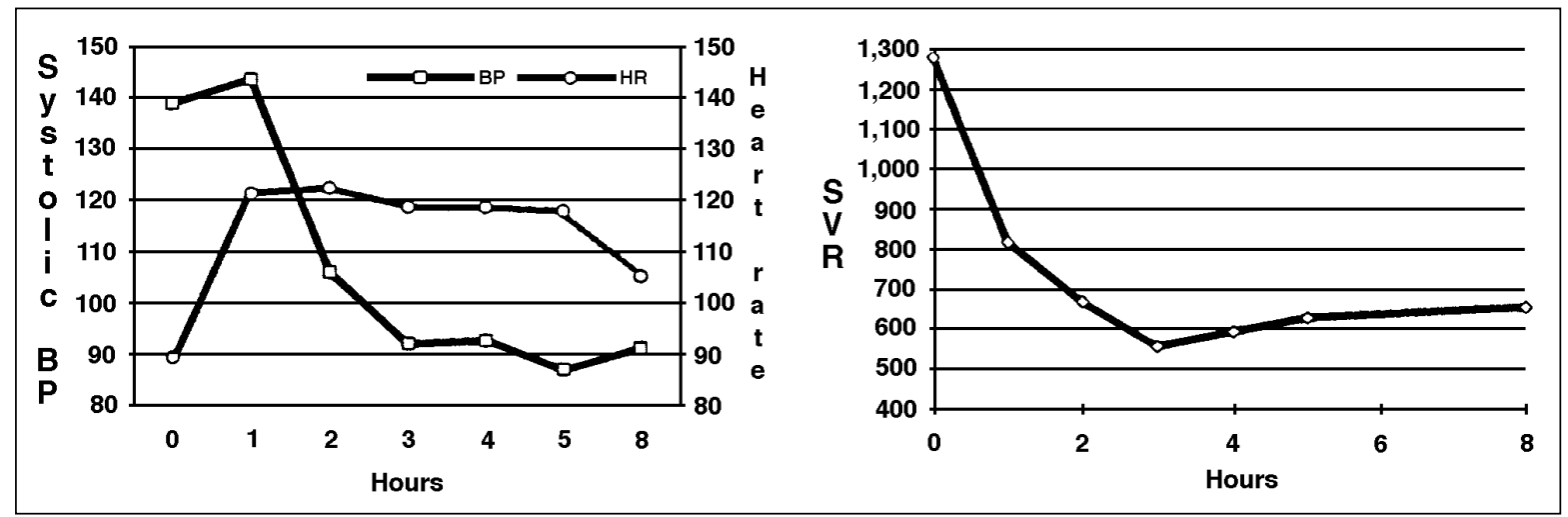

Figure 1. (Left) Mean systolic blood pressure $(\square)$ and heart rate (O) of three patients after their first dose of $0.3 \mu g / k g I L-1 \alpha$. (Right) Mean systemic vascular resistance (SVR) of these same patients.

however, the tolerance of IL-1 $\alpha$ was not improved [19]. In this study, somnolence was noted after IL-1 $\alpha$ treatment in several patients, and may have been related to the medications given for chills or nausea. Electroencephalograms obtained after the first dose showed diffuse slowing consistent with a metabolic encephalopathy. One patient treated at the highest dose level $(1.0 \mu \mathrm{g} / \mathrm{kg}$ plus indomethacin) experienced severe somnolence, agitation and confusion; all symptoms resolved within $48 \mathrm{~h}$ after IL-1 $\alpha$ was stopped. Another patient treated at $0.3 \mu \mathrm{g} / \mathrm{kg}$ plus indomethacin was observed to have confusion and delusional ideation; this toxicity resolved soon after treatment was discontinued. One patient treated with $0.3 \mu \mathrm{g} / \mathrm{kg}$ IL- $1 \alpha$ plus indomethacin suffered a myocardial infarction after his fourth dose accompanied by ventricular tachycardia that was cardioverted successfully.

Cardiovascular effects were the most worrisome side effects that interfered with dose escalation in all the clinical trials of IL-1 and were well described in the IL- $1 \alpha$ trial [16]. Systolic blood pressure (BP) rose during the first 30 min after treatment but decreased consistently thereafter, reaching $90 \mathrm{~mm} \mathrm{Hg}$ or lower between $3 \mathrm{~h}$ and $5 \mathrm{~h}$ after treatment with the higher doses. Hypotension was managed with boluses of normal saline; however, at dose levels $\geq 0.3$ $\mathrm{mcg} / \mathrm{kg}$, it was necessary to support the BP with i.v. phenylephrine, dopamine or both. The hypotension resulted from a marked decrease in the systemic vascular resistance (SVR) and not from a decline in cardiac output. IL-1 $\alpha$ treatment resulted in a significant drop in SVR, which in $3 \mathrm{~h}$ had decreased by $50 \%$ or more (Fig. 1). Heart rate and cardiac output rose in a compensatory fashion in response to the drop in BP and SVR. The cardiac output failed to increase further when patients received fluid loading, and a decrease in the ejection fraction was observed in one patient at the highest dose of IL-1. The cardiovascular effects of IL-1 $\alpha$ were the same as those observed in septic shock, i.e., tachycardia, hypotension, decreased systemic vascular resistance and some degree of myocardial dysfunction.

As described in Table 3, IL-1 treatment in all studies had both early and late effects on the bone marrow and peripheral blood. IL-1 $\alpha$ treatment increased the number of granulocytes in the peripheral blood $4 \mathrm{~h}$ after treatment, consistent with a demargination effect; however, the high number of bands that appeared in the peripheral blood indicates that IL-1 also caused an egress of cells from the maturation-storage compartment of the marrow. In the Memorial Sloan-Kettering and BRMP studies, significant increases in the platelet counts were observed one to two weeks after treatment, and increased megakaryocytes were also observed in bone marrow biopsies performed after seven days of IL-1 treatment in the IL-1 study at the BRMP. Dose-related increases in serum IL-6 levels also were noted after IL-1 treatment in both studies [16, 17].

The BRMP also conducted a phase I trial of IL- $\beta$ (Syntex) with a study design and endpoints exactly the same

Table 3. Hematologic effects noted in clinical trials of IL-1 $\alpha$ and IL-1 $\beta$

Peripheral blood

$\Delta$ Increases WBC

$\Delta$ Increases neutrophilic bands and neutrophils

$\Delta$ Delayed increase in platelet counts

\section{Bone marrow}

$\boldsymbol{\Delta}$ Increases cellularity

Increases relatively mature cells of granulocyte lineage

$\Delta$ Increases megakaryocytes

Hematopoietic growth factors

$\Delta$ Induces IL-6

$\Delta$ Induces G-CSF 
as for the IL-1 $\alpha$ study [20]. Toxicities observed in this trial were similar to those described for IL- $1 \alpha$, and the MTDs were identical as well. Uncommon toxicities included hypertension accompanied by pulmonary edema in one patient at the $0.1 \mu \mathrm{g} / \mathrm{kg}$ dose level, and atrial fibrillation in one patient treated at the $0.3 \mu \mathrm{g} / \mathrm{kg}$ dose level. Dose-limiting toxicity was reached at the $1.0 \mu \mathrm{g} / \mathrm{kg}$ dose level where one patient had severe long-lasting hypotension, and another patient developed bronchospasm.

Investigators at New York University Medical Center also conducted a phase I trial of IL-1 $\alpha$ (Immunex; Seattle, WA) using a 2-h i.v. infusion for five days [21]. The dose-limiting toxicity was hypotension requiring i.v. fluids and occurred at the $3 \mu \mathrm{g} / \mathrm{m}^{2}$ dose level (approximately $0.1 \mu \mathrm{g} / \mathrm{kg}$ ). They defined the MTD as $2 \mu \mathrm{g} / \mathrm{m}^{2}$. Other toxicities were similar to those observed in the previously mentioned phase I trials. Hematopoietic effects were also similar: increased granulocytes, increased bone marrow cellularity and a delayed increase in platelets. Although IL-1-mediated increases in bone marrow progenitors were not seen, there was a significant dose-dependent increase in the number of circulating granulocyte, macrophage, granulocyte-macrophage and eosinophil colony forming units (CFUs) in the peripheral blood prior to and at the end of the 2-h IL- $1 \alpha$ infusion on day 5. In this study, monocyte cytotoxicity assays were performed using the HT29 colon cancer cell line with and without the in vitro addition of IFN- $\gamma$. IL- $1 \alpha$ increased direct monocyte cytotoxicity and augmented the monocyte cytotoxicity observed with the addition of IFN- $\gamma$ in vitro.

IL-1 $\beta$ (Syntex) by s.c. administration was tested in a cohort of patients with advanced cancer [22]. Dose levels of 10 to $100 \mathrm{ng} / \mathrm{kg}$ were delivered daily for seven days. Toxicities were similar to IL- $1 \beta$ given intravenously; however, atrial fibrillation and an episode of deep venous thrombosis were seen in the s.c. trial. Dose-dependent increases in WBCs were seen lasting 12 to 14 days after treatment. Similarly, platelet counts increased five to seven days after IL-1 treatment and remained elevated for up to four weeks.

The BRMP performed a trial of IL- $1 \alpha$ injected into a single s.c. or cutaneous lesion in melanoma patients once daily for five days [23]. Groups of at least three patients each were treated with IL- $1 \alpha$ beginning with 0.001 $\mu \mathrm{g} / \mathrm{kg}$. The IL- $1 \alpha$ dose was escalated by half-log increments between cohorts up to $0.1 \mu \mathrm{g} / \mathrm{kg}$. Toxicity was relatively minor with this method of administration. Fever and chills were common but were grade 2 or less in all but one patient. There was erythema at the site of IL- $1 \alpha$ injection in 8 of 15 patients.

\section{Combination IL-1 and IL-2 Phase I Trials}

Some investigators combined IL-1 and IL-2 to enhance cellular immune function. At the University of Chicago, cancer patients were treated with five dose levels of IL- $1 \alpha$ (Dainippon) by s.c. injection, ranging from 0.001 to 0.1 $\mu \mathrm{g} / \mathrm{kg} /$ day, with IL-2 at $1.5 \mathrm{MU} / \mathrm{m}^{2} /$ day [24]. Increases in natural killer cell activity from 1.3 to 22 times baseline were seen in all patients; however, there was no relation of this finding to IL-1 dose level. All patients displayed increases in granulocytes, eosinophils and platelets. The peak granulocyte count correlated with the IL-1 dose. Minor responses were seen in one renal cell and one melanoma patient.

A similar trial was performed with IL-1 $\beta$ (Syntex) given by i.v. infusion over $30 \mathrm{~min}$ at doses from 0.005 to $0.2 \mu \mathrm{g} / \mathrm{kg} /$ day on four consecutive days. This IL-1 regimen was combined with IL-2 at $0.1 \mu \mathrm{g} / \mathrm{m}^{2} /$ day by continuous infusion concurrent with the IL-1 administration [25]. These cycles were repeated weekly for eight weeks. Treatment was well tolerated. Lymphokine activated killer cell (LAK) activity in the peripheral blood was highest at the lowest IL-1 dose level and decreased with increasing IL-1 $\beta$ dose. The number of circulating $\mathrm{CD}^{+} 6^{+}$cells did increase in a dose-dependent fashion with IL-1. Increases in the number of $\mathrm{CD}_{25} 5^{+}$cells, CD45RO ${ }^{+}$cells and monocyte tumor cell cytolysis also were noted but had no relationship to IL-1 $\beta$ dose. Complete and partial responses were seen in five of the 15 patients: colon cancer (3), renal cell carcinoma (1) and melanoma (1).

\section{Phase II Trials}

IL-1 $\alpha$ could have antitumor activity against melanoma based on its direct antiproliferative activity in vitro against human melanoma cell lines, its ability to induce IFNs and IL-2 (both of which have activity alone and in combination in melanoma patients) and its ability to enhance the activity of cytotoxic T cells and other effector cells. It can also induce hemorrhagic necrosis in some animal tumor models.

Investigators at Stanford University reported preliminary results of a trial of IL-1 $\beta$ (Syntex) in melanoma patients [26]. Patients received doses ranging from 0.001 to $0.1 \mu \mathrm{g} / \mathrm{kg}$ i.v. for five days every six weeks. Of nine evaluable patients, there was one complete and two partial responses in patients with nonvisceral sites of metastasis.

Metastatic melanoma patients were treated at the BRMP with IL-1 $\alpha$ (Dainippon) at $0.1 \mu \mathrm{g} / \mathrm{kg}$ i.v. over $15 \mathrm{~min}$ once daily for seven days [27]. Indomethacin $50 \mathrm{mg}$ p.o. or p.r. was given starting $2 \mathrm{~h}$ before the first dose and continued every $8 \mathrm{~h}$ during IL-1 treatment based on animal studies demonstrating enhanced antitumor activity of the combination. Treatment was repeated once after a two-week rest. Forty-nine patients were entered into this study; all were 
evaluable for response. Chills, fever, headache, nausea, vomiting and myalgia were common but were grade 1 or 2 . Grade 3 hypotension requiring i.v. pressors (phenylephrine) occurred in one-third of patients and was limited to the first dose in all but two patients, who required pressors with their first and second doses. All toxicities were worse with the first dose and gradually improved during the therapy. Of the 14 evaluable patients with predominantly visceral metastases, there were no partial or complete remissions. Of the 35 patients with predominantly nonvisceral metastatic disease, there were four responses: one complete and three partial, for a response rate of $11 \%$ (95\% confidence interval: 5\%-26\%). The duration of the complete response was $37^{+}$months, and the durations of the partial responses were each six months.

Redman et al. conducted a phase II trial of rIL-1 $\beta$ in patients with metastatic renal cell carcinoma [28]. IL-1 $\beta$ (Syntex) was administered at $50 \mathrm{ng} / \mathrm{kg}$ i.v. daily for five days on a 28-day schedule. There were no complete or partial responders among the 16 evaluable patients. Grades I and II fever, rigors, hypotension and weight gain were typical toxicities. One patient had grade IV neurotoxicity (seizures) and one had grade III somnolence. They also noted an increase from mean pretreatment levels of soluble IL-2 receptor and IL-6 levels. Neutrophilic leukocytosis and mild thrombocytosis were also observed.

\section{Trials of IL-1 as a Hematopoietic Agent}

The dose escalation of many antineoplastic drugs is limited by granulocytopenia and thrombocytopenia. In vitro and preclinical studies demonstrated that IL-1 induced the production of many hematopoietic growth factors such as G-CSF, GM-CSF, M-CSF and IL-6. IL-1 also acted synergistically with these cytokines and growth factors to stimulate hematopoiesis and promote the proliferation and differentiation of hematopoietic progenitor cells in vitro [29-31]. In addition, IL-1 upregulated the expression of receptors for IL-1, GM-CSF and IL-3 on hematopoietic progenitor cells [32]. Preclinical studies showed that IL-1 accelerated the recovery of granulocytes and platelets when given after chemotherapy or sublethal radiation, and it had a protective effect if given before lethal radiation or chemotherapy $[13,33,34]$. Because phase I studies showed IL-1 to have the ability to increase granulocytes and platelets in cancer patients who had not received chemotherapy, several investigators combined IL-1 with myelosuppressive chemotherapy regimens to test its ability to ameliorate granulocytopenia and thrombocytopenia following chemotherapy.

To determine if granulocyte recovery could be accelerated by IL-1 $\beta$, as suggested by animal models [17], investigators at Memorial Sloan-Kettering gave two days of IL-1 $\beta$ after three days of 5 -fluorouracil (5-FU) at $833 \mu \mathrm{g} / \mathrm{m}^{2} /$ day.
Patients had previously received a cycle of 5-FU alone and were used as their own controls. IL-1 $\beta$ was escalated in sequential cohorts of patients from $0.002 \mu \mathrm{g} / \mathrm{kg}$ to $0.1 \mu \mathrm{g} / \mathrm{kg}$. There was a trend toward fewer days of neutropenia after IL-1 $\beta$ treatment; however, the difference did not reach statistical significance. No thrombocytopenia resulted from the 5-FU treatment, so no conclusion about thrombopoietic effects of IL-1 $\beta$ could be reached.

A clinical trial was performed at the BRMP combining IL-1 $\alpha$ with high-dose carboplatin to test if IL- $1 \alpha$ could be useful in ameliorating chemotherapy-induced thrombocytopenia [35]. One group of patients received IL-1 $\alpha$ before chemotherapy because preclinical studies indicated that IL-1 was capable of protecting the bone marrow from chemotherapy- or radiation therapy-induced myelosuppression [13, 34]. IL-1 $\alpha$ was given after chemotherapy to another group to test its ability to promote hematopoietic recovery. The first-cycle platelet counts of each of the eight patients in the control group dropped below $100,000 / \mu \mathrm{L}$ with a nadir platelet count that ranged from 5,000 to $56,000 / \mu \mathrm{L}$ (median $19,000 / \mu \mathrm{L}$ ). IL- $1 \alpha$ treatment before carboplatin at $0.03,0.10$, and 0.30 $\mu \mathrm{g} / \mathrm{kg}$ had no effect on the first-cycle platelet count nadir, duration of thrombocytopenia, time to decline below, or time to recover above 100,000 platelets $/ \mu \mathrm{L}$ compared to the control group. IL-1 $\alpha$ treatment after carboplatin at 0.03 and 0.1 $\mu \mathrm{g} / \mathrm{kg}$ similarly had no effect. However, at $0.3 \mu \mathrm{g} / \mathrm{kg} \mathrm{IL}-1 \alpha$ after carboplatin, the median time to recovery of 100,000 platelets was 16 days compared to 23 days in the IL- $1 \alpha$ before carboplatin group and 21 days in the control group (Fig. 2). In addition, two of the five patients treated with IL- $1 \alpha 0.1 \mu \mathrm{g} / \mathrm{kg}$ after carboplatin and three of the ten patients treated with IL-1 $\alpha 0.3 \mu \mathrm{g} / \mathrm{kg}$ after carboplatin had markedly less thrombocytopenia after treatment, with mean platelet nadirs of $165,000 / \mu \mathrm{L}$ (range $91,000-332,000 / \mu \mathrm{L}$ ).

Vadhan-Raj and colleagues at M.D. Anderson Hospital conducted a study of continuous i.v. infusion of IL- $1 \alpha$ (Immunex) after carboplatin $400 \mu \mathrm{g} / \mathrm{m}^{2}$ in patients with recurrent ovarian cancer [36]. During the first month, cohorts of patients received four days of IL- $1 \alpha$ alone at escalating doses from 0.1 to $10.0 \mu \mathrm{g} / \mathrm{m}^{2} / 24 \mathrm{~h}$ (approximately $0.0025-0.25$ $\mu \mathrm{g} / \mathrm{kg}$ ). During the second month, the patients were treated with carboplatin $400 \mu \mathrm{g} / \mathrm{m}^{2}$ alone. Patients received carboplatin followed by IL-1 $\alpha$ in the third month. Treatment with IL-1 $\alpha$ resulted in significantly fewer days of severe thrombocytopenia $(<100,000 / \mu \mathrm{L}$ or $<50,000$ platelets $/ \mu \mathrm{L})$ when the third month was compared to the second month. A few patients who had documented platelet nadirs at $<100,000 / \mu \mathrm{L}$ with carboplatin alone no longer had such declines with the subsequent cycles that included IL- $1 \alpha$. The number of days of leukopenia $(<2,000 \mathrm{WBC} / \mu \mathrm{L})$ was also significantly reduced. The maximum tolerated dose of IL- $1 \alpha$ was $3 \mu \mathrm{g} / \mathrm{kg} / \mathrm{day}$ 


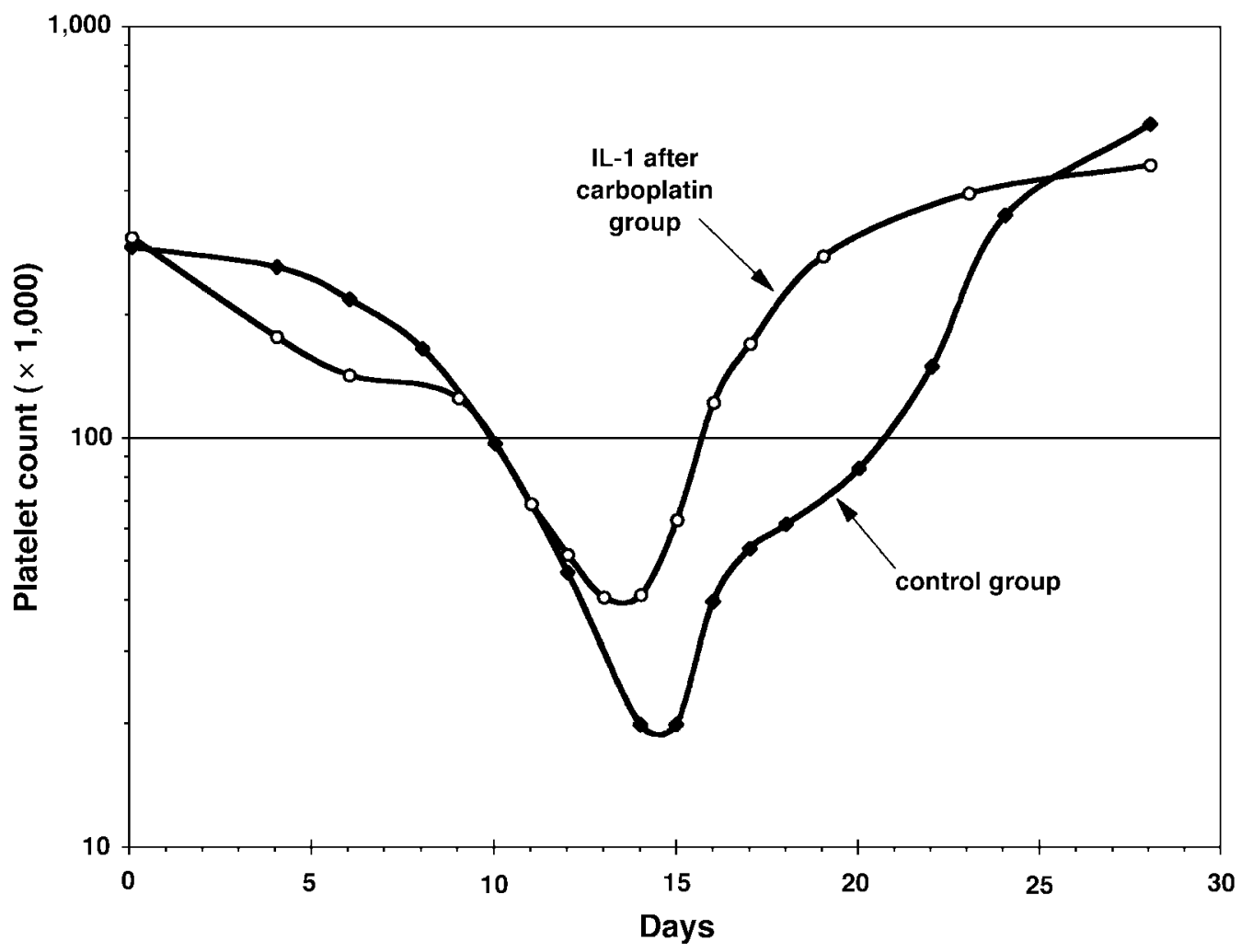

Figure 2. Median platelet counts of the groups treated with $0.3 \mu \mathrm{g}$ per kilogram interleukin $1 \alpha$ after carboplatin (O) and the control group ( () . Carboplatin was administered on day 0 . The interleukin $1 \alpha$-after group received 5 doses of interleukin $1 \alpha$ from day 1 through day 5. The control group received carboplatin alone.

(approximately $0.075 \mu \mathrm{g} / \mathrm{kg} / \mathrm{day}$ ). Four out of 18 patients showed decreases in CA-125 and minor tumor responses after the first cycle when IL-1 $\alpha$ was given alone.

A phase I dose escalation study of IL-1 $\alpha$ and high-dose cyclophosphamide $\left(1.5 \mathrm{~g} / \mathrm{m}^{2}\right)$ in patients with advanced cancer was conducted by the Eastern Cooperative Oncology Group and reported by Schuchter et al. to evaluate the myeloprotective and myelorestorative effects of IL-1 [37]. Three different schedules of IL-1 in relationship to cyclophosphamide were examined. IL-1 $\alpha$ was given i.v. over $15 \mathrm{~min}$ for five days, either prior to cyclophosphamide (day -5 to -1 ), overlapping (day -2 to +2 ), or after cyclophosphamide $($ day +1 to +5$)$. There was a significant but transient increase in WBC $24 \mathrm{~h}$ after administration of IL-1, independent of IL-1 dose or schedule (reported through the first two dose levels of 0.03 and $0.06 \mu \mathrm{g} / \mathrm{kg}$ ). The overlapping administration of IL-1 and cyclophosphamide was associated with more severe neutropenia which was doserelated. No data were reported regarding platelet counts.
Patients are being enrolled onto the next higher dose level of IL-1, $0.1 \mu \mathrm{g} / \mathrm{kg}$.

Other investigators have examined the bone marrow restorative effects of IL-1 with platinum-based chemotherapy for gynecologic malignancies [38]. Chemotherapy consisting of carboplatin, cyclophosphamide and cisplatin was first given to patients without IL-1. Cycles 2 and 3 included IL-1 $\alpha$ (Immunex) by s.c. injection at dose levels of 0.3 to $10.0 \mu \mathrm{g} / \mathrm{m}^{2}$ for four days after chemotherapy. There was no definite improvement in platelets or neutrophil counts comparing cycle 1 to subsequent cycles.

Based on preclinical data that demonstrated IL-1 to have a radioprotective effect, Wheeler et al. conducted a trial of the myeloprotective effects of IL-1 given by 4-h i.v. infusion for four days prior to administration of ${ }^{131}$ I-labeled CC49 monoclonal antibody [39]. This was compared to 15 patients treated at another institution with radiolabeled CC49 alone and showed a trend toward reduced nadirs with IL-1 versus radioimmunotherapy (RIT) alone (WBC 3.1 versus $1.8 \times 10^{3}$, 
absolute granulocyte count (AGC) 1.7 versus $0.7 \times 10^{3}$, platelets 77 versus $46 \times 10^{3}$ ) but these differences were not statistically significant. They concluded that pretherapy with IL-1 did not alter RIT toxicity sufficiently to permit meaningful dose escalation.

\section{Bone Marrow Transplantation Studies}

The Medicine Branch of the NCI conducted a study of IL-1 $\alpha$ (Dainippon) as a myeloprotective agent given for seven days prior to high-dose chemotherapy with ifosfamide, carboplatin and etoposide (ICE) followed by autologous bone marrow transplant (ABMT) [40, 41]. The IL-1 $\alpha$ was given as a 3-h infusion daily for seven days. The dose of IL-1 was increased gradually from $0.05 \mu \mathrm{g} / \mathrm{kg}$ up to $0.3 \mu \mathrm{g} / \mathrm{kg}$ on subsequent days of administration. Toxicities observed with the 3-h infusion regimen included hypotension, pulmonary edema, fever, chills, nausea, vomiting, abdominal pain and headache. The MTD of IL- $1 \alpha$ was $0.2 \mu \mathrm{g} / \mathrm{kg} / \mathrm{day}$. Elevated levels of IL- 6 and G-CSF were detected in $80 \%$ of the patients. IL-1 $\alpha$ treatment shortened the durations of granulocytopenia and hospitalization after ABMT, compared to historical controls treated with ICE alone. Although the effect was statistically significant, it was small. Thrombocytopenia was not affected in this trial. These findings suggest that IL-1 $\alpha$ has a protective effect for granulocytic precursors when given before chemotherapy.

Investigators at Duke University have given IL-1 $\beta$ (OCT-43) following high-dose chemotherapy with cyclophosphamide, carboplatin and carmustine (BCNU) with ABMT [42]. The IL-1 $\alpha$ was administered s.c. for seven days over a range of doses from 0.004 to $0.032 \mu \mathrm{g} / \mathrm{kg}$. Toxicity from IL- $1 \beta$ was moderate and consisted of fever, chills, confusion, hypotension and pain at the injection sites. No significant effects were noted on recovery of platelets or granulocytes, although there was a marked increase in the bone marrow CFU-GM per $10^{5}$ cells compared to historical controls or patients who had received G-CSF or GM-CSF.

Weisdorf et al. conducted a phase I/II dose escalation clinical trial of IL-1 $\alpha$ (Immunex) administered after ABMT in 40 patients with Hodgkin's disease or non-Hodgkin's lymphoma [43, 44]. IL-1 $\alpha$ was given as a daily 6-h i.v. infusion on days 0 to day +13 at 0.1 to $10 \mu \mathrm{g} / \mathrm{m}^{2} /$ day. Fourteen consecutive patients receiving no IL-1 $\alpha$ (seven with autologous bone marrow stem cells and seven with peripheral blood stem cells) were evaluated as control patients. Toxicity included fever, severe chills and fatigue. Hypotension was dose-limiting in both patients receiving $10 \mu \mathrm{g} / \mathrm{m}^{2} /$ day. The MTD was $3.0 \mu \mathrm{g} / \mathrm{m}^{2} /$ day and led to significantly earlier neutrophil recovery (ANC $>500 / \mathrm{ml}$ ) with a median of 12 days (range 11 to 27) compared to control patients or patients receiving 0.1 to $1.0 \mu \mathrm{g} / \mathrm{m}^{2} /$ day of IL- $1 \alpha$ (median 27 days; range 9 to 63). IL-1 $\alpha$ patients' bone marrows were significantly enriched with committed myeloid progenitor cells at day +14 . Significant elevations in G-CSF and IL- 6 were detected in the plasma of the IL-1 $\alpha$-treated patients. IL- $1 \alpha$ treated patients also showed a strong trend toward earlier freedom from transfusions for red blood cells and platelets. The earlier hematopoietic engraftment in transplant patients treated with $3.0 \mu \mathrm{g} / \mathrm{m}^{2} /$ day of IL- $1 \alpha$ allowed earlier discharge from the hospital (median 25 versus 37 days for the control or low-dose IL-1 $\alpha$ patients), which resulted in a median reduction in hospital charges by $\$ 38,000$.

Nemunaitis et al. conducted a phase I trial of rhIL-1 $\beta$ (Syntex) in acute myelogenous leukemia (AML) patients undergoing ABMT (with 4-hydroxycyclophosphamide [4-HC]-purged marrow in 9 of the 17 study patients) $[45,46]$. All 17 patients received a preparative regimen of busulfan and cyclophosphamide, and 14 of the 17 patients also received TBI. The three dose levels of rhIL-1 $\beta$ were $0.01,0.02$ and $0.05 \mu \mathrm{g} / \mathrm{kg} /$ day given by i.v. infusion over $30 \mathrm{~min}$ on days 0 to +14 . Fevers and chills were noted in all 17 patients within $30 \mathrm{~min}$ of initiation of rhIL-1 $\beta$. Hypotension was noted $5 \mathrm{~h}$ to $8 \mathrm{~h}$ after rhIL-1 $\beta$ in 14 of the 17 patients, and normal saline or dopamine was required in $30 \%$ of patients to treat hypotension. Other toxicities included nausea, vomiting, diarrhea, myalgias and headache. Patients who received rhIL-1 $\beta$ required fewer days to achieve an ANC $>500 / \mu \mathrm{L}$ compared to historical controls that did not receive CSFs (25 versus 34 days). The rhIL-1 $\beta$ patients also appeared to have a reduced incidence of infection between days 0 and +28 (12\% versus $23 \%)$. Platelet recovery was not different between these AML study patients and historical controls. Overall two-year survival was better for rhIL-1 $\beta$ patients compared to historical control patients (30\% versus $20 \%$ ).

\section{Discussion}

IL-1 has the potential to be useful in the treatment of cancer based on its direct and indirect antitumor effects and its hematopoietic effects. The phase I trials noted a variety of toxicities consistent with the pleiotropic effects of IL-1. The most troublesome toxicity that limits utility of IL-1 is hypotension. The profound hemodynamic effects of IL- $1 \alpha$ are similar to those noted with other biologic agents, such as endotoxin, TNF or IL-2. The mechanism for IL-1-induced hypotension has not been established but could be due to the induction of prostaglandins $\mathrm{E}_{2}$ or $\mathrm{I}_{2}\left(\mathrm{PGE}_{2}, \mathrm{PGI}_{2}\right)$, prostacyclin, platelet-activating factor, TNF or nitric oxide. In the BRMP studies, IL-1 did not increase TNF levels, and indomethacin did not decrease the incidence or severity of hypotension. The delayed and prolonged hypotension, and the lack of effect of indomethacin are consistent with experiments showing IL-1 to be a potent inhibitor of vascular 
smooth muscle contraction. IL-1 induces production of nitric oxide which activates guanylate cyclase leading to an increase in cyclic guanosine monophosphate (GMP), which then leads to an inhibition of vascular smooth muscle contraction [47]. Supporting this mechanism of hypotension is the finding of significant increases in serum nitrate levels after IL- $1 \alpha$ treatment, especially in patients with more severe hypotension.

Animal experiments have shown that arginine derivatives can block the enzymatic formation of nitric oxide and reverse the hypotension induced by TNF and by IL-1 through the nitric oxide pathway [48, 49]; thus, nitrate antagonists may be clinically useful for management of hypotension induced by IL-1. Methylene blue is another agent that decreases nitrate-induced vasodilation by inhibiting guanylate cyclase and reducing cyclic GMP levels in smooth muscle. A trial is under way at the BRMP to evaluate methylene blue to treat hypotension from IL-1. Although changes in cyclic GMP levels have been observed in patients after methylene blue treatment, it is too early to assess if this approach will be successful in ameliorating IL-1 toxicity. All the hematopoietic effects of IL-1 have been greater with increasing doses of IL-1. Therefore, to maximize its potential utility, a way of limiting its undesirable toxicity is necessary.

Dose escalation of many chemotherapeutic agents is limited by granulocytopenia and thrombocytopenia. G-CSF and GM-CSF do not attenuate thrombocytopenia and permit only a moderate dose escalation in chemotherapy $[50,51]$. Phase I and II studies of IL- $1 \alpha$ and IL- $1 \beta$ have demonstrated that they cause early granulocyte count elevations and delayed platelet count elevations after treatment. IL- $1 \alpha$ also accelerated the recovery of platelets after high-dose carboplatin therapy. The expansion of megakaryocytes (MKs) in the bone marrow and a dose-related increase in serum levels of G-CSF and IL-6 have also been noted in clinical trials. A critical question is whether the beneficial effects of IL-1 can be replaced by a combination of the cytokines it is known to induce (G-CSF and IL-6) or whether IL-1 has unique hematopoietic activities.

Since IL-1 increases IL-6 levels, increased IL-6 levels may partially account for increased platelet counts observed after IL-1 administration. However, in vitro studies have also demonstrated that IL-1 has more effects on hematopoiesis than simply increasing IL-6 levels. Bruno and Hoffman [52] found the addition of IL- $1 \alpha$ and IL- 6 to CD34+DR ${ }^{+}$cultures resulted in the appearance of CFU-MK-derived colonies, suggesting that IL- 6 required the presence of IL- $1 \alpha$ for stimulation of MK colonies. Briddell et al. [53] studied the role of cytokines in sustaining long-term human megakaryocytopoiesis in vitro. They used CD34+DR ${ }^{-}$cells as the inoculum of cells to initiate long-term bone marrow cultures
(LTBMCs). LTBMCs receiving no cytokines contained no assayable CFU-MK, no assayable BFU-MK and no observable MKs. These in vitro studies showed that IL-1 can activate and expand the number of MK progenitors, CFU-MK, from primitive CD $34^{+} \mathrm{DR}^{-}$cells. They showed GM-CSF and IL-3 are each capable of promoting CFU-MK and BFU-MK, and the action of these cytokines is additive. Also, IL-1 $\alpha$, but not IL- 6 , amplifies the ability of IL-3 to promote the formation of BFU-MK-derived colonies. However, IL-1 $\alpha$ was incapable of promoting BFU-MK-derived colony formation by itself. Repeat IL- 6 additions to LTBMCs led to mature MKs for only four weeks. Repeat IL-1 $\alpha$ or IL-3 additions to LTBMCs led to mature MKs for eight and 10 weeks. GM-CSF additions led to MKs for 10 weeks. The addition of GM-CSF, IL-1 $\alpha$, and IL-3 alone or in combination each led to the appearance of significant numbers of MKs during LTBMC. However, IL-6-supplemented cultures led to relatively few MKs - probably because MKs were absent in the initial CD34 ${ }^{+} \mathrm{DR}^{-}$cell population, and IL-6 lacks the ability to generate these cells from the cellular inoculum. By contrast, cultures supplemented with GM-CSF, IL-1 $\alpha$ or IL-3 produced greater numbers of MKs, which is consistent with the primary action of these cytokines being on the CFU-MK and/or BFU-MK generated from the CD34+DR- cells. IL-6 appears to act as a potent maturation factor acting on more differentiated megakaryocytic elements. Their results suggest that CD34 ${ }^{+} \mathrm{DR}^{-}$cells are capable of initiating long-term megakaryocytopoiesis in vitro, and that a hierarchy of cytokines exists capable of sustaining this process.

Ikebuchi et al. [54] have suggested that the synergistic activities of IL-1 on primitive hematopoietic cells may be indirect. They analyzed the time courses of colony formation from cultures of day-2 post-5-FU marrow cells supported by IL-1 $\alpha$, IL-6, or G-CSF alone or in combination with IL-3. In the presence of IL-3, both G-CSF and IL- 6 , but not IL- $1 \alpha$, hastened the development of colonies and increased the number of multilineage colonies relative to cultures of IL-3 alone. Their observations suggest that the synergistic effect of IL-1 is likely due to induction of secondary growth factors, including IL-6 and G-CSF, by accessory cells in culture.

The use of IL-1 as a myeloprotective agent was studied in Hornung's experiments at the BRMP, which showed that IL-1 can prevent stem cell depletion in animals undergoing high-dose chemotherapy in serial passage of marrow experiments [55]. Repetitive treatment using GM-CSF appears to exhaust the stem cell pool, but IL-1 $\alpha$ can protect the bone marrow from chemotherapy. This could be important with regard to repetitive high-dose chemotherapy regimens in curable/treatable malignancies.

The fact that IL-1 $\alpha$ did not have a beneficial effect when given before carboplatin may be due to an insufficient duration 
of IL-1 treatment. Animal studies that demonstrated the marrow-protective effects of IL-1 $\alpha$ when given before high-dose cyclophosphamide revealed that IL-1 $\alpha$ had no effect when given by i.v. bolus, but exerted a marked effect when given intraperitoneally ( $R$. Wiltrout, personal communication). Therefore, more prolonged i.v. infusion or s.c. administration of IL- $1 \alpha$ before chemotherapy may demonstrate a protective effect. Preliminary positive results from a trial using a 3-h i.v. infusion of IL-1 $\alpha$ for seven days before high-dose chemotherapy and ABMT are consistent with the notion that IL- $1 \alpha$ could have a significant myeloprotective effect [40, 41]. However, the results of other studies argue against any significant myeloprotective effect of IL-1. Schuchter's study of IL-1 and cyclophosphamide showed only a transient increase in WBC $24 \mathrm{~h}$ after administration of IL-1 [37]. Wheeler's study showed pretherapy IL-1 did not alter RIT toxicity sufficiently to permit meaningful dose escalation [39]. The results of these clinical trials support the conclusion that IL-1 is not dramatically myeloprotective.

Gordon and Hoffman reported that IL-1, IL-6, and KL (c-kit ligand) can secondarily modulate megakaryocytopoiesis by inducing marrow accessory cells to release hematopoietic growth factors with MK-colony stimulating activity [56]. They also reported that KL, IL-6, IL-11 and leukemia inhibitory factor have the ability to promote the effects of IL-3 on CFU-MK proliferation.

Recently, Kaushansky and Lok reported in vivo results which strongly suggest that the ligand for c-Mpl is thrombopoietin $[57,58]$. When the above-listed IL-1 studies were done, thrombopoietin had not yet been identified.

One of the potential applications of IL-1 is to help expand bone marrow ex vivo. Studies by Moore et al. [31] indicate the limited number of pluripotent progenitor cells in 4-HC purged marrow can be expanded to large numbers with IL-1 in combination with other cytokines. Also, IL-1 seemed to endow such progenitor cells with responsiveness to CSFs or IL-3. Synergism between IL-6 and M-CSF or
IL-3 is also seen in the high proliferative potential colony forming cell assay, and supradditive interactions take place between IL-1, IL-6, and G-CSF, M-CSF or GM-CSF.

\section{SUMMARY}

Over the last six years, many clinical trials of IL-1 have been conducted. These studies have demonstrated that IL-1 can be safely given to human cancer patients. Toxicities, although manageable, can be severe. A variety of doses, routes and schedules of administration has been tested with most toxicities and biologic effects being dose-related. By itself, IL-1 has little antitumor activity against melanoma, renal cell carcinoma, ovarian carcinoma or other diseases, and combinations with other cytokines or chemotherapy remain to be tested.

IL-1 has modest hematopoietic effects that may not be worth the toxicity necessary to achieve them. The best hematopoietic, especially megakaryocytopoietic, effects will likely be produced by sequential combinations of cytokines. The hematopoietic effects of IL-1 do not appear to be unique, e.g., IL-6 has similar thrombopoietic effects. Although some researchers have differences of opinion as to whether the hematopoietic effects of IL-1 are all indirect via induction of secondary cytokines, these effects can probably be produced with other cytokines with a more favorable toxicity profile than IL-1.

Because of the demonstrated toxicities of IL-1 and the lack of evidence for unique hematopoietic effects, almost all of the pharmaceutical companies that make IL-1 plan to discontinue (or have already discontinued) production of IL-1. For now, the reality is that IL-1 is not likely to be studied further in phase III trials. However, IL-1 may have a limited role in expansion of bone marrow ex vivo following stem cell harvest, which could allow dose-intensive chemotherapy to be elevated to new levels in the treatment of curable/treatable types of cancer.

Reprinted from Stem CelLs 1996;14:164-176.

\section{REFERENCES}

1 Atkins E. The pathogenesis of fever. Physiol Rev 1960;40:580-646.

2 Dinarello CA. Biology of interleukin 1: Federation of American Societies for Experimental Biology. Biology 1988;2:108-115.

3 Lomedico PT, Gubler CP, Hellman CP et al. Cloning and expression of murine interleukin 1 cDNA in Eschericha coli. Nature 1984;312:458-462.

4 Dower SK, Kronheim SR, March CJ et al. The cell surface receptors for interleukin 1 alpha and interleukin 1 beta are identical. Nature 1986;324:266-269.
5 Nakamura S, Kashimoto S, Kajikawa F et al. Combination effect of recombinant human interleukin $1 \alpha$ with antitumor drugs on syngeneic tumors in mice. Cancer Res 1991;51:215-221.

6 Onozaki K, Matsushima K, Aggarwal BB et al. Human interleukin 1 is a cytocidal factor for several tumor cell lines. $\mathrm{J}$ Immunol 1985;135:3962-3968.

7 Crump WL III, Owen-Schaub LB, Grimm EA. Synergy of human recombinant interleukin 1 with interleukin 2 in the generation of lymphokine activated killer cells. Cancer Res 1989;49:149-153. 
8 Herman J, Dinarello CA, Kew MC et al. The role of interleukin 1 (IL-1) in tumor NK cell interactions. Correction of defective NK cell activity in cancer patients by treating target cells with IL-1. J Immunol 1985;135:2882-2886.

9 Yamashita U, Shirakawa F. Restoration of impaired T cell functions in tumor-bearing mice by the administration of interleukin 1. Gann 1987;78:270-278.

10 Neville ME. Antitumor effects of interleukin $1 \beta$ : inhibition of angiogenesis. Proc Annu Meet Assoc Cancer Res 1990;31:1741a.

11 Philip R, Epstein LB. Tumor necrosis factor as immunomodulator and mediator of monocyte cytotoxicity induced by itself, gamma-interferon and interleukin 1. Nature 1986;323:86-89.

12 Nakai S, Hirai Y. The therapeutic potential of interleukin 1 beta in the treatment of chemotherapy or radiation induced myelosuppression and in tumor therapy. Biotherapy 1989;1:339-354.

13 Neta R, Douches S, Oppenheim J. Interleukin 1 is a radioprotector. J Immunol 1987;136:2483-2488.

14 Laver J, Abboude M, Gasparetto C et al. Effects of IL-1 on hematopoietic progenitors after myelosuppressive chemotherapy. Biotherapy 1989;1:293-300.

15 Ozaki Y, Ohashi T, Minami A et al. Enhanced resistance of mice to bacterial infection induced by recombinant human interleukin $1 \alpha$. Infect Immun 1987;55:1436-1440.

16 Smith JW II, Urba WJ, Curti BD et al. The toxic and hematologic effects of interleukin 1 alpha administered in a phase I trial to patients with advanced malignancies. J Clin Oncol 1992;10:1141-1152.

17 Crown J, Jakubowski A, Kemeny $\mathrm{N}$ et al. A phase I trial of recombinant human interleukin $1 \beta$ alone and in combination with myelosuppressive doses of 5-fluorouracil in patients with gastrointestinal cancer. Blood 1991;78:1420-1427.

18 Okusawa S, Gelfand JA, Ikejima T et al. Interleukin 1 induces a shock-like state in rabbits. Synergism with tumor necrosis factor and the effect of cyclooxygenase inhibition. J Clin Invest 1988;81:1162-1172.

19 Smith JW II, Urba WJ, Steis R et al. Phase II trial of interleukin 1 alpha (IL-1 $\alpha$ ) in combination with indomethacin (IND) in melanoma patients (pts). Proc ASCO 1991;10:705a.

20 Steis R, Smith JW II, Janik J et al. Phase I study of recombinant IL-1 beta (Syntex). Proc ASCO 1991;10:211a.

21 Dennis D, Chachoua S, Caron D et al. Biologic activity of interleukin 1 (IL-1) alpha in patients with refractory malignancies. Proc ASCO 1992;11:830a.

22 Kanz L, Birken R, Brugger W et al. Biological activities of subcutaneous (s.c.) rhIL-1 $\beta$ in cancer patients. Blood 1992;80:357a.

23 Janik JE, Smith JW II, Urba WJ et al. Phase I trial of intratumoral interleukin 1 alpha (IL-1 $\alpha$ ). "Melanoma and Biology of the Neural Crest.” Keystone Symposia, Taos, NM, 1992.
24 Lestingi TM, Vogelzang NJ, Richards JM et al. Phase I trial of recombinant interleukin $1 \alpha$ (IL-1) and recombinant interleukin 2 (IL-2). Proc ASCO 1993;12:976a.

25 Triozzi PL, Kim JA, Martin EW et al. Phase I trial of escalating doses of Interleukin $1 \beta$ in combination with a fixed dose of Interleukin 2. J Clin Oncol 1995;13:482-489.

26 Starnes HF, Hartman G, Torti F et al. Recombinant human interleukin $1 \beta$ (IL-1 $\beta$ ) has anti-tumor activity and acceptable toxicity in metastatic malignant melanoma. Proc ASCO 1991;10:292a.

27 Janik JE, Miller LL, Longo DL et al. Phase II trial of Interleukin $1 \alpha$ and indomethacin in treatment of metastatic melanoma. J Natl Cancer Inst 1996;88:44-49.

28 Redman BG, Abubaker YC, Chou T et al. Phase II trial of recombinant interleukin $1 \beta$ in patients with metastatic renal cell carcinoma. J Immunother 1994;16:211-215.

29 Fibbe WE, Van Damme J, Billiau A et al. Interleukin 1 induces human marrow stromal cells in long-term culture to produce granulocyte colony-stimulating factor and macrophagecolony-stimulating factor. Blood 1988;71:430-435.

30 Tosato G, Jones KD. Interleukin 1 induces interleukin 6 production in peripheral blood monocytes. Blood 1990;75:1305-1310.

31 Moore MAS. Clinical implications of positive and negative hematopoietic stem cell regulators (Review: Stratton Lecture 1990). Blood 1991;78:1-19.

32 Dubois CM, Ruscetti FW, Keller JR et al. In vivo interleukin 1 (IL-1) administration indirectly promotes type II IL-1 receptor expression on hematopoietic bone marrow cells: novel mechanism for the hematopoietic effects of IL-1. Blood 1991;78:2841-2847.

33 Castelli MP, Black PL, Schneider M et al. Protective, restorative, and therapeutic properties of recombinant human IL-1 in rodent models. J Immunol 1988;140:3830-3837.

34 Futami H, Jansen R, MacPhee MJ et al. Chemoprotective effects of recombinant human IL-1 $\alpha$ in cyclophosphamide-treated normal and tumor-bearing mice. J Immunol 1990;145:4121-4130.

35 Smith JW II, Longo DL, Alvord WG et al. The effects of treatment with interleukin $1 \alpha$ on platelet recovery after high-dose carboplatin. N Engl J Med 1993;328:756-761.

36 Vadhan-Raj S, Kudelka A, Garrison L et al. Effects of interleukin $1 \alpha$ on carboplatin-induced thrombocytopenia in patients with recurrent ovarian cancer. J Clin Oncol 1994;12:707-714.

37 Schuchter L, Neuberg D, Atkins M et al. A phase I study of interleukin 1 alpha and high-dose cyclophosphamide in patients with advanced cancer. Proc ASCO 1994;13:133a.

38 Bookman MA, Caron DA, Hogan WM et al. Phase-1 evaluation of dose-intense chemotherapy with interleukin $1 \alpha$ (IL-1 $\alpha$ ) for gynecologic malignancies. Proc ASCO 1993;12:868a.

39 Wheeler RH, Meredith RF, Saleh MN et al. A phase II trial of IL-1 plus radioimmunotherapy (RIT) in patients with metastatic colon cancer. Proc ASCO 1994;13:295a. 
40 Wilson WH, Bryant G, Jain V et al. Phase I study of infusional interleukin $1 \alpha$ (IL-1) with ifosfamide (I), CBDCA (C), and etoposide (E) (ICE) and autologous bone marrow transplant (BMT). Proc Am Soc Clin Oncol 1992;11:335a.

41 Wilson WH, Bryant G, Fox M et al. Interleukin $1 \alpha$ administered before high-dose isosfamide (I), CBDCA (C), and etoposide (E) (ICE) with autologous bone marrow rescue shortens neutrophil recovery: a phase I/II study. Proc ASCO 1993;12:937a.

42 Vredenburgh J, Ross M, Kurtzberg J et al. Phase I trial of interleukin $1 \beta$ (IL-1 $\beta$ ) following high-dose chemotherapy and autologous bone marrow transplantation (ABMT). Blood 1991;78:6a.

43 Weisdorf DJ, Katsanis E, Verfaillie C et al. Interleukin $1 \alpha$ after autologous transplantation for lymphoma/Hodgkin's disease: clinical and hematologic effects. Blood 1992;80:1321a.

44 Weisdorf D, Katsanis E, Verfaillie C et al. Interleukin $1 \alpha$ administered after autologous transplantation: phase I/II clinical trial. Blood 1994;84:2044-2049.

45 Nemunaitis J, Buckner CD, Press O et al. Phase I trial with interleukin $1 \beta$ (IL-1 $\beta$ ) in patients undergoing autologous bone marrow transplantation (ABMT) for acute myelogenous leukemia (AML). Blood 1991;78:8a.

46 Nemunaitis J, Applebaum FR, Lilleby K et al. Phase I study with recombinant human interleukin $1 \beta$ in patients undergoing autologous bone marrow transplant for acute myelogenous leukemia. Blood 1994;83:3473-3479.

47 Beasley D, Schwartz JH, Brenner BM. Interleukin 1 induces prolonged L-arginine-dependent cyclic guanosine monophosphate and nitrite production in rat vascular smooth muscle cells. J Clin Invest 1991;87:602-608.

48 Kilbourn RG, Gross SS, Jubran A et al. $\mathrm{N}^{\mathrm{G}}$-methyl-L-arginine inhibits tumor necrosis factor-induced hypotension: implications for the involvement of nitric oxide. Proc Natl Acad Sci USA 1990;87:3629-3632.

49 Kilbourn RG, Gross SS, Lodato JA et al. Inhibition of interleukin 1-alpha-induced nitric oxide synthase in vascular smooth muscle and full reversal of interleukin 1-alpha-induced hypotension by N-omega-amino-L-arginine. J Natl Cancer Inst 1992;84:1008-1016.

50 Crawford J, Ozer H, Stoller R et al. Reduction by granulocyte colony-stimulating factor of fever and neutropenia induced by chemotherapy in patients with small-cell lung cancer. N Engl J Med 1991;325:164-170.

51 Nemunaitis J, Rabinowe SN, Singer JW et al. Recombinant granulocyte-macrophage colony-stimulating factor after autologous bone marrow transplantation for lymphoid cancer. $\mathrm{N}$ Engl J Med 1991;324:1773-1778.

52 Bruno E, Hoffman R. Effect of interleukin 6 on in vitro human megakaryocytopoiesis: its interaction with other cytokines. Exp Hematol 1989;17:1038-1041.

53 Briddell RA, Brandt JE, Leemhuis TB et al. Role of cytokines in sustaining long-term human megakaryocytopoiesis in vitro. Blood 1994;79:332-337.

54 Ikebuchi K, Ihle JN, Hirai Y et al. Synergistic factors for stem cell proliferation: further studies of the target stem cells and the mechanism of stimulation by interleukin 1 , interleukin 6, and granulocyte-colony stimulating factor. Blood 1988;72:2007-2014.

55 Hornung RL, Longo DL. Hematopoietic stem cell depletion by restorative growth factor regimens during repeated high-dose cyclophosphamide therapy. Blood 1992;80:77-83.

56 Gordon MS, Hoffman R. Growth factors affecting human thrombocytopoiesis: potential agents for the treatment of thrombocytopenia. Blood 1992;80:302-307.

57 Lok S, Kaushansky K, Holly RD et al. Cloning and expression of murine thrombopoietin cDNA and stimulation of platelet production in vivo. Nature 1994;369(6481):565-568.

58 Kaushansky K, Lok S, Holly RD et al. Promotion of megakaryocyte progenitor expansion and differentiation by the c-Mpl ligand thrombopoietin. Nature 1994;369(6481):568-571. 